\title{
Chain Elongation Influence in Copolymerization with Different Diesters of Norbornene 2,3-Dicarboxylic Acid Monomers via ROMP under Air Atmosphere
}

\author{
Sâmia D. Braga, ${ }^{a}$ Vanessa B. Vieira, ${ }^{b}$ Cristina V. Silva-Neta,${ }^{b}$ Nouga C. Batista,${ }^{b}$ Larissa R. Fonseca, ${ }^{c}$ \\ Benedito S. Lima-Neto, ${ }^{c}$ Geraldo E. Luz Jr. ${ }^{*, b}$ and José Luiz. S. Sá ${ }^{*, b}$ \\ aPrograma de Pós-Graduação em Química, Departamento de Química, Universidade Federal do Piauí, \\ 64049-550 Teresina-PI, Brazil \\ ${ }^{b}$ GERATEC, Centro de Ciências da Natureza, Universidade Estadual do Piauí, 64002-150 Teresina-PI, Brazil \\ 'Instituto de Química de São Carlos, Universidade de São Paulo, CP 780, 13560-970 São Carlos-SP, Brazil
}

\begin{abstract}
Diesters of norbornene 2,3-dicarboxylic acid (NBE-(COOR $\left.)_{2}\right)$, in which $\mathrm{R}$ is an alkyl group, were synthesized from one-pot synthesis method with 5-norbornene-2,3-dicarboxylic acid and methanol and ethanol. The new monomers were, respectively, the dimethyl ester NBE- $\left(\mathrm{COOCH}_{3}\right)_{2}$ and diethyl ester NBE- $\left(\mathrm{COOCH}_{2} \mathrm{CH}_{3}\right)_{2}$. Norbornene was mixed with these monomers at different proportions and copolymerized via ring-opening metathesis polymerization (ROMP) with $1^{\text {st }}$ generation Grubbs' catalyst. All experiments were conducted under air atmosphere to obtain the isolated polymer. Yield results show that elongation of the $\mathrm{R}$ group influenced the copolymerization process. At the same co-monomer proportion, the yield decreases as a function of the $\mathrm{R}$ group elongation. Thermogravimetric analysis (TGA) was performed and, in all cases, more than one thermal degradation process was observed. The first process was assigned to pendent group degradation, whereas the second process was assigned to main chain degradation. These thermal processes were also influenced by different elongation of the aliphatic group of the pendent chain.
\end{abstract}

Keywords: copolymer, norbornene, ROMP, TGA

\section{Introduction}

Ring-opening metathesis polymerization (ROMP) is an important technique to obtain unsaturated polymers. ${ }^{1,2}$ Furthermore, the mixture of different monomers allows the synthesis of several copolymers. Norbornene (NBE) is a classic olefinic monomer widely utilized in ROMP and when it is mixed with norbornadiene (an olefinic monomer with two double bonds) the resultant material shows different characteristics from those of homopolymers, polynorbornene (polyNBE) and polynorbornadiene (polyNBD). The literature ${ }^{1,3-6}$ describes other examples of copolymers from two or more monomers via metathesis with interesting properties.

Ahmed et al. ${ }^{7}$ evaluated the influence of different proportions of NBE and 5-norbornene-2,3-dicarboxylic acid and 5-norbornene-2,3-dicarboxylic acid bistrimethylsilyl ester in the polydispersity of the respective copolymers. Later, Vargas et al. ${ }^{8}$ studied the copolymerization of aminomonomers with NBE and, more recently, Yang et al. ${ }^{6}$

*e-mail: geraldoeduardo@gmail.com; zeluizquimica@gmail.com presented the shape memory study of a copolymer of NBE cyano derivative with NBE $\varepsilon$-caprolactone derivative. Part of these studies were conducted because when NBE is copolymerized with other monomers with hydrophilic characteristics, it may form an important copolymer with amphiphilic properties, containing hydrophobic and hydrophilic blocks. ${ }^{9}$

5-Norbornene-2,3-dicarboxylic acid and its esters are vastly used as monomers in ROMP reactions. ${ }^{7,8,10-13}$ $\left.\mathrm{NBE}-(\mathrm{COOCH})_{2}\right)_{2}$ and NBE- $\left(\mathrm{COOCH}_{2} \mathrm{CH}_{3}\right)_{2}$ are examples of 5-norbornene-2,3-dicarboxylic derived acid esters presented in the literature ${ }^{8,11,12}$ in studies of polymerization via metathesis using different metathesis catalysts. Demel et al. ${ }^{11}$ presented an interesting study on the influence of Grubbs' catalysts in the ROMP of (NBE- $\left.\left(\mathrm{COOCH}_{2} \mathrm{CH}_{3}\right)_{2}\right)$, revealing superior activity of the second Grubbs' catalyst and intermediary activity of the first generation catalysts. In addition, Kiselev et al. ${ }^{13}$ have recently conducted a study with another important focus: the influence of the pendent group of 5-norbornene2,3-dicarboxylic acid esters derived in its ROMP with $2^{\text {nd }}$ generation Hoveyda-Grubbs' catalyst. 
The present study proposes the copolymerization reactions of $\mathrm{NBE}$ and compounds derived from 5-norbornene-2,3-dicarboxylic acid obtained through the one-pot synthesis method from esterification reaction with methanol or ethanol (Scheme 1) to obtain diester of norbornene 2,3-dicarboxylic acid. The yields and thermal degradation analysis are presented in this study.

It is important to note that the syntheses of these monomers, NBE- $\left(\mathrm{COOCH}_{3}\right)_{2}$ (monomer 1) and $\mathrm{NBE}-\left(\mathrm{COOCH} \mathrm{CH}_{3}\right)_{2}$ (monomer 2) (Scheme 1), are reported in the literature, ${ }^{14}$ but not using the one-pot synthesis route. We believe that this study can contribute to report a simple and easier synthetic route for obtaining 5-norbornene-2,3-dicarboxylic acid esters. In addition, its copolymerizations with NBE, yield values, and thermogravimetric analysis (TGA) are the highlights of this work when compared with other studies in the literature. The authors report different reaction ratios when different monomers (norbornene and norbornadiene) are mixed and copolymerized via ROMP. ${ }^{4}$

\section{Experimental}

\section{General remarks}

All handling was performed under air atmosphere. All the solvents were analytically graded. Norbornene, norbornene 2,3-dicarboxylic acid, and $1^{\text {st }}$ generation Grubbs' catalyst from Aldrich were used as purchased.
One-pot synthesis of the diesters of 5-norbornene2,3-dicarboxylic acid (NBE-(COOR) ${ }_{2}$ ) monomers

Diesters of norbornene 2,3-dicarboxylic acid monomers (NBE-(COOR) $)_{2}$ ) were synthesized by reacting 5-norbornene-2,3-dicarboxylic acid (NBE- $\left.(\mathrm{COOH})_{2}\right)$ $(1.0 \mathrm{~g})$ with $20 \mathrm{~mL}$ of each alcohol, $\mathrm{R}=$ methanol (monomer 1) or ethanol (monomer 2 ), heating under reflux for $2 \mathrm{~h}$ in the presence of $\mathrm{HCl}(10 \mathrm{~mL})$. After the reaction time, the solution was evaporated until $4 \mathrm{~mL}$ of final volume. This was the solution used in the synthesis of the copolymers. $100 \mu \mathrm{L}$ were diluted in $1 \mathrm{~mL}$ of $\mathrm{CHCl}_{3}$ and then analyzed by gas chromatography mass spectrometry (GCMS). The analyzed molecules presented $\mathrm{m} / z$ compatible with the monomers proposed and the structures of the monomers were proposed from these data. The literature presents similar reports. ${ }^{9}$ Moreover, no signal was observed in the GC-MS analysis; therefore, the volume of this solution presents a known quantity of each monomer. The solutions of the NBE-(COOR $)_{2}$ monomer were used in the copolymerization reactions. Each solution $(4 \mathrm{~mL})$ contained $5.5 \mathrm{mmol}$ of monomer.

\section{Copolymerization}

In the copolymerization reactions, a solution of NBE in $\mathrm{CHCl}_{3}$ was prepared $\left(23.7 \mathrm{~mol} \mathrm{~L}^{-1}\right)$. Different volumes of monomers were mixed $(0.5,1.0$ or $1.5 \mathrm{~mL})$ with $1 \mathrm{~mL}$ of $\mathrm{CHCl}_{3} .1 .0 \mathrm{mg}$ of $1^{\text {st }}$ generation Grubbs' catalyst was

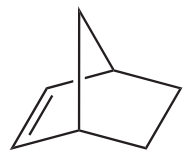

NBE

Norbornene

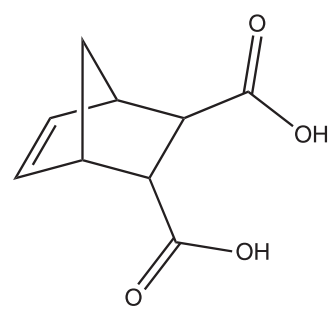

NBE- $(\mathrm{COOH})_{2}$

5-norbornene-2,3-dicarboxylic acid

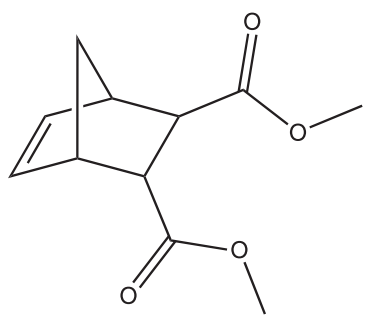

monomer 1: $\mathrm{NBE}-\left(\mathrm{COOCH}_{3}\right)_{2}$ dimethyl ester of 5-norbornene-2,3-dicarboxylic acid

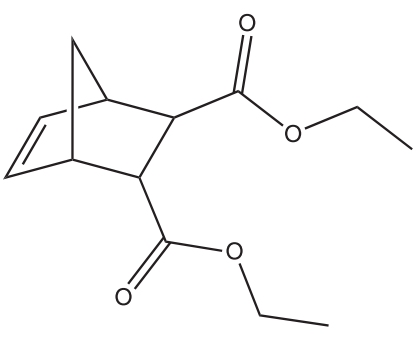

monomer 2: $\mathrm{NBE}-\left(\mathrm{COOCH}_{2} \mathrm{CH}_{3}\right)_{2}$ diethyl ester of 5-norbornene-2,3-dicarboxylic acid

Scheme 1. Structures of the monomers. 
added and the mixture remained at $50^{\circ} \mathrm{C}$ for $30 \mathrm{~min}$. After the reaction time, $5 \mathrm{~mL}$ of methanol was added and the precipitated polymer was filtered, washed with methanol, and then dried before it was weighed. The yields reported are the arithmetic means from a batch with two individual solutions, where each batch was performed in triplicate. The polymeric materials were weighed several times until its mass remains constant.

Copolymer samples were denominated $\mathrm{X}: \mathrm{Y}$ poly $\left(\mathrm{NBE}-\mathrm{co}-\mathrm{NBE}-(\mathrm{COOR})_{2}\right)$, where $\mathrm{X}(0.5,1.0$ and 1.5) denotes the volume $(\mathrm{mL})$ of $\mathrm{NBE}$ and $\mathrm{Y}(0.5,1.0$ and 1.5) denotes the volume $(\mathrm{mL})$ of NBE-(COOR $)_{2}$. The copolymers isolated were analyzed by derivative thermogravimetry (DTG) until $48 \mathrm{~h}$ after the synthesis.

\section{Analyses}

GC-MS analyses of monomers were conducted using a GCMS-QP2010 SE, Shimadzu manufactured, with EI-mass selective detector on an RTX-5MS column. The temperature was maintained at $250^{\circ} \mathrm{C}$ for $40 \mathrm{~min}$ with total column flow of $2.5 \mathrm{~mL} \mathrm{~min}^{-1}$ and split ratio of 1.0.

TGA and DTG analyses of the isolated copolymers were performed from 25 to $400{ }^{\circ} \mathrm{C}$, at $10{ }^{\circ} \mathrm{C} \mathrm{min}-1$ under $\mathrm{N}_{2}$ atmosphere.

\section{Results and Discussion}

Different volumes of NBE and NBE-(COOR $)_{2}$ were mixed and copolymerized using $1^{\text {st }}$ generation Grubbs' catalyst at $50{ }^{\circ} \mathrm{C}$ for $30 \mathrm{~min}$ under air atmosphere. The volumes of the solutions of monomers and the yields of the copolymers obtained are presented in Table 1, along with other important information related to the amount of the compounds.

Elongation of the $\mathrm{R}$ aliphatic group of the esters (from methyl to ethyl) influenced the yields of polymerization. The yields decreased when increasing the $\mathrm{CH}_{2}$ group in the aliphatic group in the presence of $0.5 \mathrm{~mL} \mathrm{NBE}$ (Table 1; entries 1-3). Access of the units of monomers to the metal center could be affected with increase of the $\mathrm{R}$ group elongation. A study using N-chelating Hoveyda II type catalyst in the ROMP of eight of norbornene2,3-dicarboxylic acid esters demonstrated that elongation of the aliphatic substituent affected the reactivity of esters insignificantly. ${ }^{13}$ Discoordination of the N-Hoveyda II catalyst allows a fast approach to independent monomeric units.

Entries 1, 4 and 6 in Table 1 show the yields when volume of NBE-(COOR $)_{2}$ is constant and volume of the NBE solution increases. In this condition, the yields decreased for monomer $\mathbf{1}$ while increased for monomers $\mathbf{2}$.

When NBE-(COOR $)_{2}$ volume was varied and volume of the NBE solution was kept constant, the yields or increased or the values were similar. For monomer 1, with 0.5 or $1.0 \mathrm{~mL}$ of NBE solution, the yield increased. For monomer $\mathbf{2}$, with $0.5 \mathrm{~mL}$ of NBE solution, the yields were similar, and with $1.0 \mathrm{~mL}$ of NBE solution, the yield decreased. With $1.5 \mathrm{~mL}$ of NBE solution the yield decreased for monomer $\mathbf{1}$ and increased for monomers 2 (Table 1).

The aliphatic groups of the ester of 5-norbornene2,3-dicarboxylic monomers influenced the yield of the copolymers. With $0.5 \mathrm{~mL}$ of monomers $\mathbf{1}$ and $\mathbf{2}$ (Table 1; entry 1 ), the copolymer yields were ca. $41 \%$ with

Table 1. Volume proportions of NBE:NBE-(COOR) 2 (monomers 1 and 2 ) and yields of the copolymers obtained

\begin{tabular}{|c|c|c|c|c|c|c|c|c|}
\hline \multirow[b]{2}{*}{ entry } & \multirow{2}{*}{$\begin{array}{c}\text { Total volume } \\
\text { (NBE:NBE-S) } \\
\text { mL }\end{array}$} & \multirow{2}{*}{$\begin{array}{c}\mathrm{NBE}^{\mathrm{c}} \\
(\text { concentration / } \\
\left.\left(\mathrm{mol} \mathrm{L}^{-1}\right)\right) / \mathrm{mmol}\end{array}$} & \multirow{2}{*}{$\begin{array}{c}\mathrm{NBE}-\mathrm{S}^{\mathrm{c}} \\
(\text { concentration } / \\
\left.\left(\mathrm{mol} \mathrm{L}^{-1}\right)\right) / \mathrm{mmol}\end{array}$} & \multirow{2}{*}{$\begin{array}{c}\text { NBE: NBE-S } \\
\text { ratio / } \\
\left(\mathrm{mol} \mathrm{L}^{-1}\right)\end{array}$} & \multirow{2}{*}{$\begin{array}{l}\text { Total monomer } \\
(\text { concentration / } \\
(\mathrm{mol} \mathrm{L}-1)) / \mathrm{mmol}\end{array}$} & \multirow[b]{2}{*}{ Mon:Ru ${ }^{\mathrm{d}}$} & \multicolumn{2}{|c|}{ Yield / \% } \\
\hline & & & & & & & Monomer 1 & Monomer 2 \\
\hline 1 & $\begin{array}{c}2.0 \\
(0.5: 0.5)\end{array}$ & $\begin{array}{l}11.8 \\
(5.9)\end{array}$ & $\begin{array}{l}0.687 \\
(0.34)\end{array}$ & 17.2 & $\begin{array}{c}12.5 \\
(6.25)\end{array}$ & 10330.6 & 41.5 & 25.5 \\
\hline 2 & $\begin{array}{c}2.5 \\
(0.5: 1.0)\end{array}$ & $\begin{array}{l}11.8 \\
(4.7)\end{array}$ & $\begin{array}{c}1.37 \\
(0.55)\end{array}$ & 8.65 & $\begin{array}{c}13.2 \\
(5.28)\end{array}$ & 10909.1 & 67.5 & 28.0 \\
\hline 3 & $\begin{array}{c}3.0 \\
(0.5: 1.5)\end{array}$ & $\begin{array}{l}11.8 \\
(3.9)\end{array}$ & $\begin{array}{c}2.06 \\
(0.69)\end{array}$ & 5.75 & $\begin{array}{c}13.9 \\
(4.63)\end{array}$ & 11487.6 & 70.0 & 26.7 \\
\hline 4 & $\begin{array}{c}2.5 \\
(1.0: 0.5)\end{array}$ & $\begin{array}{l}23.7 \\
(9.5)\end{array}$ & $\begin{array}{l}0.687 \\
(0.27)\end{array}$ & 34.3 & $\begin{array}{c}24.4 \\
(9.76)\end{array}$ & 20165.3 & 20.8 & 34.6 \\
\hline 5 & $\begin{array}{c}3.0 \\
(1.0: 1.0)\end{array}$ & $\begin{array}{l}23.7 \\
(7.9)\end{array}$ & $\begin{array}{c}1.37 \\
(0.45)\end{array}$ & 17.3 & $\begin{array}{c}25.1 \\
(8.37)\end{array}$ & 20743.8 & 32.2 & 22.4 \\
\hline 6 & $\begin{array}{c}3.0 \\
(1.5: 0.5)\end{array}$ & $\begin{array}{c}35.5 \\
(11.8)\end{array}$ & $\begin{array}{l}0.687 \\
(0.23)\end{array}$ & 51.5 & $\begin{array}{c}36.2 \\
(12.1)\end{array}$ & 29917.3 & 15.2 & 34.8 \\
\hline
\end{tabular}

${ }^{a}$ Volumes of the monomers for ratios of $1 \mathrm{~mL}$ of $\mathrm{CHCl}_{3}$ in the reaction; ${ }^{\mathrm{b}} \mathrm{S}$ : $(\mathrm{COOR})_{\mathrm{x}}, \mathrm{NBE}$ :NBE-S ratio in volume:volume; ${ }^{\mathrm{c}} \mathrm{monomer}$ amount; ${ }^{\mathrm{d}}$ ratio in mol:mol, where Mon is monomer and Ru is ruthenium; NBE: norbornene. 
monomer 1 and ca. 25\% with monomer 2. However, this tendency is not clear in the volumes of 1.0 and $1.5 \mathrm{~mL}$ of NBE with $0.5 \mathrm{~mL}$ of monomers 1 and $\mathbf{2}$. For monomer $\mathbf{1}$, the yield decreased when increasing the NBE volume (Table 1; entries 1, 4 and 6). For monomer 2, the yield increased or remained constant, ca. 35\% (Table 1; entries 1, 4 and 6). The bulk of the aliphatic group is important in polymerization because the larger presence of the norbornene ester favors the copolymerization yield.

A previous work ${ }^{1}$ discussed that the different ring characteristic causes difference in the ring tension, which can favor the process of polymerization via metathesis; the higher the ring strain, the more favorable the process. However, for the esters of norbornene studied in this work, two characteristics should be observed: the ring strain and the aliphatic group elongation. It is clear that these properties are balanced as a function of the substituent of each NBE-dicarboxylic ester. However, the results when increasing $\mathbf{1}$ or $\mathbf{2}$ volume make it evident that there is predominance of the aliphatic group bulk.

Figure 1 shows the TGA and DTGA curves of the 0.5:0.5, 1.5:0.5 and 0.5:1.5 poly(NBE-co-NBE-(COOR $)_{2}$ ) proportions. The loss of weight before $200{ }^{\circ} \mathrm{C}$ can be attributed to evaporation of solvent, unreacted monomers and oligomers. All curves presented two main degradation steps, the first one occurred at ca. $260{ }^{\circ} \mathrm{C}$ and the second one varying from ca. 300 to $320^{\circ} \mathrm{C}$, which were associated with degradation of the pendent group and of the main chain of the copolymer, respectively.
It is important to notice that the thermal degradation of all materials is strongly influenced by less packing due to the pendent groups of the co-monomers; a typical thermal degradation of the poly(NBE) is observed at ca. $475^{\circ} \mathrm{C} .{ }^{1,3}$

We performed the TGA for poly(NBE-co-NBE-(COOR $)_{2}$ ) synthesized in the proportions $0.5: 0.5,1.5: 0.5$ and 0.5:1.5. The fist process at ca. $260{ }^{\circ} \mathrm{C}$ persisted, relative to the pendent group, whereas the main second process had its value shifted as a function of the NBE:NBE-dicarboxylic ester ratio (Figures 1a-f). These degradation processes were very similar when the co-monomers were NBE- $\left(\mathrm{COOCH}_{3}\right)_{2}$ and diethyl ester NBE-( $\left.\mathrm{COOCH}_{2} \mathrm{CH}_{3}\right)_{2}$ when comparing the $0.5: 0.5$ and $1.5: 0.5$ ratios. On the other hand, in the 0.5:1.5 NBE:NBE-dicarboxylic ester ratio the variation of $20^{\circ} \mathrm{C}$ is noted. The lower degradation temperature of the main chain was observed when NBE- $\left(\mathrm{COOCH}_{2} \mathrm{CH}_{3}\right)_{2}$ is in the proportion of $0.5: 1.5$ (Figure 1f). It may be related with the lesser packing of the main chain. Other standard characterizations such as gel permeation chromatography (GPC) and nuclear magnetic resonance (NMR) of ${ }^{1} \mathrm{H}$ and ${ }^{13} \mathrm{C}$ were not performed because the copolymers were insoluble.

Our research group has already discussed the different influence in reactivity in the copolymerization process of NBE and NBD (norbornadiene) during copolymerization; coordination of the monomer in the metal center generates a particular reactivity ratio as a function of the co-monomers. Those variables influence the yields and thermal behavior. ${ }^{3}$
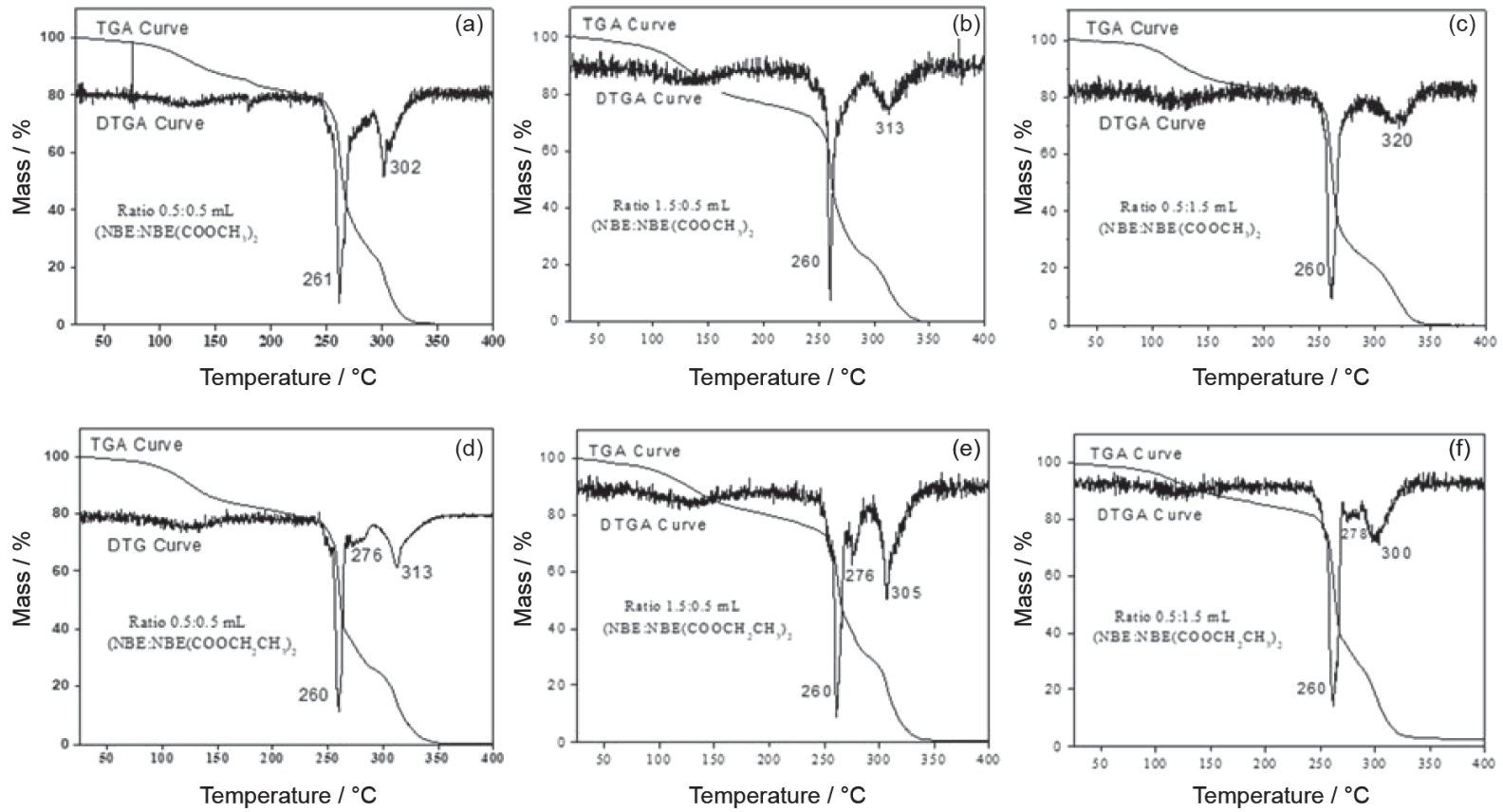

Figure 1. TGA and DTGA curves for 0.5:0.5; 1.5:0.5 and 0.5:1.5 poly(NBE-co-NBE-(COOR) $)_{2}$ ) proportions with monomer $\mathbf{1}$ (a, b and c) and monomer $\mathbf{2}$ (d, e and f). 


\section{Conclusions}

Esters derivatives from 5-norbornene-2,3-dicarboxylic were copolymerized with norbornene as co-monomer in different [monomer]:[co-monomer] proportions using $1^{\text {st }}$ generation Grubbs' catalyst under air atmosphere. The copolymers obtained were characterized by TGA and had their solubility tested, in all case were insoluble. Yields of the copolymers changed as a function of the pendent group bulk and of norbornene proportion.

The results and discussion presented in this paper help understand the reactivity of the 5-norbornene2,3-dicarboxylic ester derivatives when mixed and copolymerized with monomers with properties comparable to those of norbornene. We believed that the variables here presented, the ratio of co-monomers and their pendent group are important to direct application in this monomer class in ring opening metathesis copolymerization (ROMCP). The literature shows that studies on 5-norbornene2,3-dicarboxylic ester derivatives are important for the development of new materials, which can be verified by the relevant number of recent publications. ${ }^{8,10-13}$ In contrast, in this study, the use of air atmosphere makes the means more robust, being a new contribution to science.

\section{Acknowledgments}

The authors are indebted to CAPES, CNPq (307559/2015-7) and FAPESP for their financial support.

\section{References}

1. Bielawski, C. W.; Grubbs, R. H.; Prog. Polym. Sci. 2007, 32, 1.

2. Grubbs, R. H.; Tetrahedron 2004, 60, 7117.

3. Sá, J. L. S.; Nascimento, E. S. P.; Fonseca, L. R.; Lima-Neto, B. S.; J. Appl. Polym. Sci. 2013, 127, 3578.
4. Carvalho Jr., V. P.; Ferraz, C. P.; Lima-Neto, B. S.; Eur. Polym. J. 2012, 48, 341; Ferraz, C. P.; Fonseca, L. R.; Tomazetti, V.; Silva, F. C. S.; Lima-Neto, B. S.; Carvalho Jr., V. P.; New J. Chem. 2016, 40, 9424; Chaves, H. K.; Ferraz, C. P.; Carvalho Jr., V. P.; Lima-Neto, B. S.; J. Mol. Catal. A: Chem. 2014, 385, 46; Raptopoulos, G.; Kyriakou, K.; Mali, G.; Scarpellini, A.; Anyfantis, G. C.; Mavromoustakos, T.; Pitsikalis, M.; Paraskevopoulou, P.; Polymers 2017, 9, 141.

5. Miftakhov, M. S.; Mikheev, V. V.; Torosyan, S. A.; Biglova, Y. N.; Gimalova, F. A.; Menshov, V. M.; Mustafin, A. G.; Tetrahedron 2014, 70, 8040.

6. Yang, D.; Huang, W.; Yu, J.; Jiang, J.; Zhang, L.; Xie, M.; Polymer 2010, 51, 5100.

7. Ahmed, S. R.; Bullock, S. E.; Cresce, A. V.; Kofinas, P.; Polymer 2003, 44, 4943.

8. Vargas, J.; Colin, E. S.; Tlenkopatchev, M. A.; Eur. Polym. J. 2004, 40, 1325.

9. Cummins, C. C.; Schrock, R. R.; Cohen, R. E.; Chem. Mater. 1992, 4, 27; Albagli, D.; Bazan, G.; Wrighton, M. S.; Schrock, R. R.; J. Am. Chem. Soc. 1992, 114, 4150; Komiya, Z.; Pugh, C.; Schrock, R. R.; Macromolecules 1992, 25, 6586.

10. Chadlia, A.; Farouk, M. M.; Carbohydr. Res. 2010, 345, 264.

11. Demel, S.; Schoefberger, W.; Slugovc, C.; Stelzer, F.; J. Mol. Catal. A: Chem. 2003, 200, 11.

12. Amir-Ebrahimi, V.; Corry, D. A. K.; Hamilton, J. G.; Rooney, J. J.; J. Mol. Catal. A: Chem. 1998, 133, 115.

13. Kiselev, S. A.; Lenev, D. A.; Lyapkov, A. A.; Semakin, S. V.; Bozhenkova, G.; Verpoort, F.; Ashirov, R. V.; RSC Adv. 2016, $6,5177$.

14. Haigh, D. M.; Kenwright, A. M.; Khosravi, E.; Tetrahedron 2004, 60, 7217. 